\title{
Discovery and Exploration of the Efficient Acyclic Dehydration of Hexoses in
} DMSO/Water

Taarning, Esben; Sádaba, Irantzu; Jensen, Pernille Rose; Meier, Sebastian

Published in:

ChemSusChem

Link to article, DOI:

$10.1002 /$ cssc.201902322

Publication date:

2019

Document Version

Peer reviewed version

Link back to DTU Orbit

Citation $(A P A)$ :

Taarning, E., Sádaba, I., Jensen, P. R., \& Meier, S. (2019). Discovery and Exploration of the Efficient Acyclic Dehydration of Hexoses in DMSO/Water. ChemSusChem, 12(23), 5086-5091.

https://doi.org/10.1002/cssc.201902322

\section{General rights}

Copyright and moral rights for the publications made accessible in the public portal are retained by the authors and/or other copyright owners and it is a condition of accessing publications that users recognise and abide by the legal requirements associated with these rights.

- Users may download and print one copy of any publication from the public portal for the purpose of private study or research.

- You may not further distribute the material or use it for any profit-making activity or commercial gain

- You may freely distribute the URL identifying the publication in the public portal 


\title{
Discovery and Exploration of the Efficient Acyclic Dehydration of Hexoses in DMSO/Water
}

\author{
Esben Taarning ${ }^{[\mathrm{b}]}$ Irantzu Sádaba,${ }^{[\mathrm{b}]}$ Pernille Rose Jensen, ${ }^{[\mathrm{c}]}$ and Sebastian Meier*[a]
}

\begin{abstract}
Current gaps in the development of sustainable processes include lacking strategies to systematically identify and optimize the formation of new products. The dehydration of hexoses to 5hydroxymethylfurfural (HMF) is a particularly widely studied process. In an attempt to identify a new high-selectivity conversion of glucose, quantitative NMR spectroscopy was used to screen conditions that were reported to yield high conversion of glucose, but low formation of HMF. In this manner, an olefinic six-carbon byproduct was identified. By water addition, selectivity for the compound was nearly tripled relative to previous reports. The detection of high-yielding side reactions in the formation of HMF is remarkable, considering how extensively HMF formation has been studied. High selectivity for the acyclic pathway allows hitherto unobserved intermediates in this pathway to be identified using in situ NMR spectroscopy. An additional, presumably cyclic, pathway contributes to HMF formation.
\end{abstract}

Biomass production from carbon dioxide exceeds $100 \cdot 10^{12} \mathrm{~kg}$ per year ${ }^{[1]}$ with an average content of carbohydrates near $75 \%$ (in addition to $20 \%$ lignin and $5 \%$ other compound classes). ${ }^{[2]}$ Contrary to other renewable biomass, carbohydrates are obtainable as cheap bulk chemicals. As the primary product of glycolysis and as the monomeric constituent of starch and cellulose, glucose is the most abundant carbohydrate building block. Hence, benign, efficient and tunable means to obtain fuels and plastic building blocks particularly from glucose are desirable.

Processes for the conversion of carbohydrates to chemicals often include stoichiometric dehydration, in order to reduce the oxygen content in the product molecule. Acid catalyzed dehydration of hexoses has attracted attention in the production of the cyclic product $\mathrm{HMF}^{[1 \mathrm{~b}, 3]}$ and of linear acids. ${ }^{[4]}$ Both cyclic and linear compounds are investigated as possible bio-platform molecules, from which new groups of useful chemicals can be derived. Thus, HMF has been converted to various furan derivatives, while unsaturated alpha-hydroxy acids have been

[a] Dr. S. Meier

Department of Chemistry

Technical University of Denmark

Kemitorvet Building 207, 2800-Kgs. Lyngby, Denmark

E-mail: semei@kemi.dtu.dk

[b] Dr. E. Taarning, Dr. I. Sádaba

Haldor Topsøe A/S

Haldor Topsøes Allé 1, 2800-Kgs. Lyngby, Denmark

[c] Dr. P.R. Jensen

Department of Health Technology

Technical University of Denmark

Elektrovej 349 2800-Kgs. Lyngby, Denmark

Supporting information for this article is given via a link at the end of the document. used to produce post-functionalized polyesters and upgraded monomers.

The formation of HMF has been studied extensively for several decades, but the mechanism by which it forms has remained a matter of debate.$^{[1 b, 5]}$ HMF may either form from fivemembered fructofuranose through a route encompassing cyclic intermediates $^{[6]}$ or through a route involving open-chain intermediates. ${ }^{[7]}$ Acyclic routes from glucose or fructose have been experimentally supported by the detection of new sets of byproducts $^{[4 \mathrm{~b}]}$ that are best rationalized through hypothetical acyclic intermediates including 3,4-di-deoxyglucosone-3-ene (3,4-DGE) ${ }^{[4 \mathrm{~b}, 6]}$ Low populations of open-chain carbohydrates and their poorly characterized properties, in particular their reactivity and catalyst binding, have complicated the mechanistic understanding of carbohydrate chemistry under reaction conditions. ${ }^{[8]}$ The best suited experimental approach to such understanding arguably involves NMR spectroscopy, as isomeric forms of carbohydrates can be distinguished in solution by NMR spectroscopy. NMR approaches have also proven useful to determine chemical structures in unpurified reaction mixtures, ${ }^{[9]}$ which is particularly beneficial for detecting transient intermediates that are difficult or impossible to purify. ${ }^{[10]}$

Here, we apply quantitative NMR spectroscopy on reaction mixtures that use cheap and abundant chemicals under conditions where reported yields of HMF were low at high glucose conversion. In this manner, reactions producing unexpected major byproducts are identified, which are systematically optimized to result in a non-commercial bio-based chemical at record high selectivity (Scheme 1). Using these rationales, a reaction yielding almost $50 \%$ of the non-commercial olefinic C6acid THA directly from glucose was developed (Figure 1)

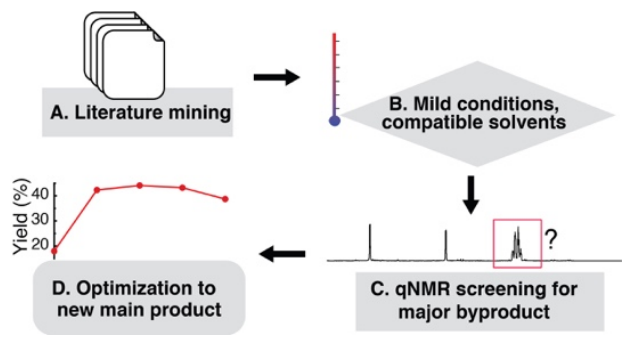

Scheme 1. Flowchart for the identification of a process giving high selectivity for a new glucose derived product from serendipitous and systematic steps.

Various metal salts reported to have low selectivity for HMF formation from carbohydrates were found to catalyze instead the formation of unforeseen byproducts. The main byproduct in the reaction mixture was identified as a trans-olefinic compound (Figure S1). This trans-olefinic compound was preferentially observed using $\mathrm{SnCl}_{4}$ in DMSO, with a selectivity for this 
A
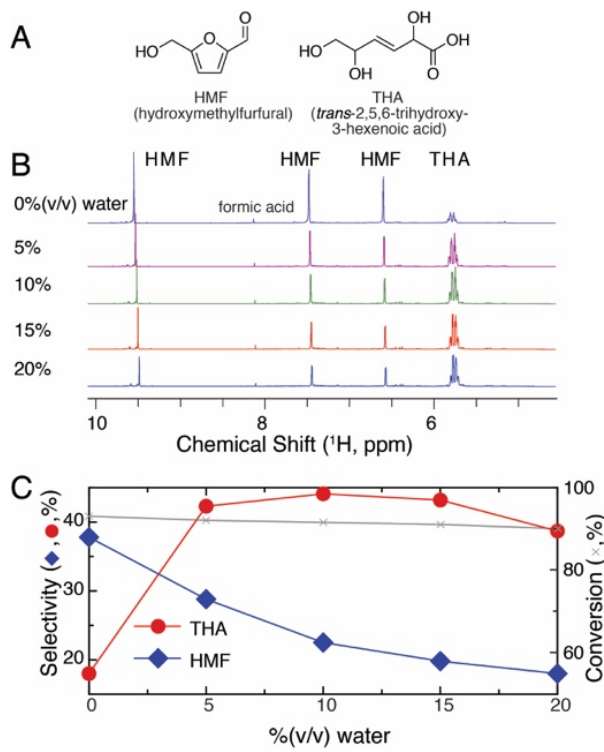

Figure 1. (A) Chemical structures of HMF and THA. (B) Product composition in a reaction of glucose $(1 \mathrm{M})$ and $\mathrm{SnCl}_{4}(0.1 \mathrm{M})$ in $\mathrm{DMSO} /$ water binary mixtures with the indicated water content ( $\%$ vol/vol at $100{ }^{\circ} \mathrm{C}, 20$ hours). The ${ }^{1} \mathrm{H}$ NMR spectral region showing narrow HMF signals and the multiplet of the THA olefins is shown. (C) Selectivity for THA and HMF and conversion of glucose determined by integrals of spectra shown in (B) and validated by quantitative ${ }^{13} \mathrm{C}$ NMR.

byproduct near $20 \%$. In situ NMR identified this olefinic compound as trans-THA (Figure S2). No cis-THA was observed, suggesting that a cis-intermediate preferably reacts to HMF, while a corresponding trans-intermediate reacts to THA (Figure 1A). Around $38 \%$ selectivity for $\mathrm{HMF}$ was observed at $100{ }^{\circ} \mathrm{C}$, consistent with previous reports on formation of $\mathrm{HMF}$ in $\mathrm{SnCl}_{4} / \mathrm{DMSO}^{[3 \mathrm{~d}, 3 \mathrm{ff}]}$

Compared to water as the solvent, polar aprotic solvents like DMSO are known to strongly affect activation energies in aldose conversion to furanics. ${ }^{[11]}$ Hence, we hypothesized that the addition of water to the $\mathrm{SnCl}_{4} / \mathrm{DMSO}$ system may stabilize acidic protons relative to the transition state and decelerate possible Brønsted acid catalyzed pathways to HMF. In addition, a water effect on product selectivity was anticipated, as the formation of both HMF and THA are stoichiometric dehydration reactions. Water addition was therefore used to tune the product selectivity in the stoichiometric dehydration reaction, stipulated by the fact that previous studies on various reaction systems had shown significant water effects on product distribution. HMF is principally considered stable in water/DMSO mixtures with very limited rehydration and conversion to levulinic acid and formic acid. Accordingly, no increase in formic acid or levulinic acid formation was observed when adding water $(5-20 \% \mathrm{v} / \mathrm{v})$ to the reaction mixture (Figure 1B). In contrast, the ratio of THA to HMF changed up to fourfold, giving NMR yields of more than $44 \%$ THA at a water content of $10 \%(\mathrm{w} / \mathrm{v})$ (Figure $1 \mathrm{~B}, \mathrm{C})$. This yield corresponds to a threefold increase in THA yield relative to the previous reports using Sn-Beta catalyzed conversions of glucose, sucrose or fructose in water or methanol. ${ }^{[4 a, 4 b]}$

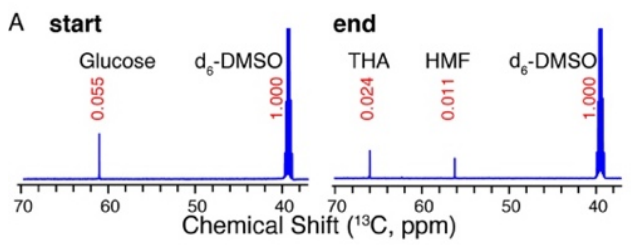

B

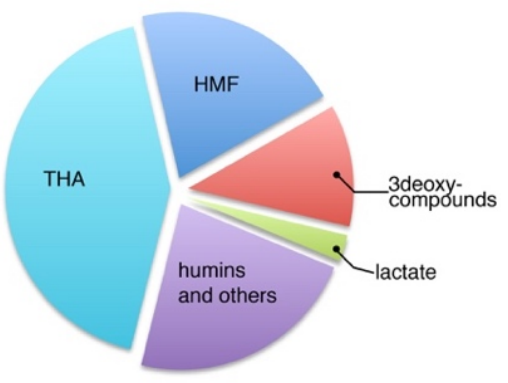

Figure 2. (A) Quantitative ${ }^{13} \mathrm{C}$ NMR spectra showing the substrate signal and the product mixture run under identical conditions. Integration is relative to the DMSO signal as the internal standard (red numbers). (B) Schematic overview of the product distribution (\%carbon) in the presence of water $(10 \% \mathrm{vol} / \mathrm{vol})$.

Quantitative ${ }^{1} \mathrm{H}$ and ${ }^{13} \mathrm{C}$ NMR spectra were used to quantify the residual reaction products, which are mostly comprised of polymeric humins, 3-deoxy compound byproducts (Figure 2, Figure S3) and lactate. Approximately $23 \%$ of carbon balance are not accounted for by the main soluble products and are ascribed to humins and minor byproducts. Water concentrations above $10 \%(w / v)$ were found to increase humin formation. The formation of furanics, THA, 3- deoxy compounds and retro-aldol products mirrors the pathways catalyzed by Sn-containing zeolites near $160^{\circ} \mathrm{C}{ }^{[4 b]}$ The tuning of product distribution by water resembles recent discoveries of water ${ }^{[12]}$ and alkali ion ${ }^{[13]}$ effects at the active site of heterogeneous Sn(IV) catalysts under such industrially relevant conditions.

High selectivity for acyclic products of glucose conversion forms a promising basis for new mechanistic insight into the relevant pathways. Low reaction temperatures and the use of homogeneous catalyst made $\mathrm{SnCl}_{4} / \mathrm{DMSO} /$ water systems amenable to mechanistic studies by in situ NMR spectroscopy. The reactivity of glucose and fructose was compared under identical reaction conditions by using both substrates in an equimolar mixture (Figure 3) The reaction was followed by ${ }^{1} \mathrm{H}-{ }^{13} \mathrm{C}$ HSQC NMR spectroscopy to yield high-quality baseline-resolved signals. Resultant reaction time courses are displayed in Figure 3 , showing that fructose reacted 30 -fold faster than glucose. The increased reactivity of fructose is a possible consequence of the higher open-chain fraction of fructose as compared to glucose. $\mathrm{Sn}(\mathrm{IV})$ has previously been suggested to exert its catalytic activity by coordinating open chain glucose, fructose or enol species as five-membered chelate structures. ${ }^{[3 \mathrm{~d}]}$ Consistent with this functionality, free open-chain fructose was not observed in the reaction mixture, possibly due to its chelation and reactivity (Figure S4). The rapid conversion of fructose to THA by $\mathrm{SnCl}_{4} / \mathrm{DMSO} /$ water permits full conversion within 24 hours at temperatures as low as $40^{\circ} \mathrm{C}$. The resultant THA product is a diastereomeric compound with chiral centers at C2 and C5 (Figure S5). 

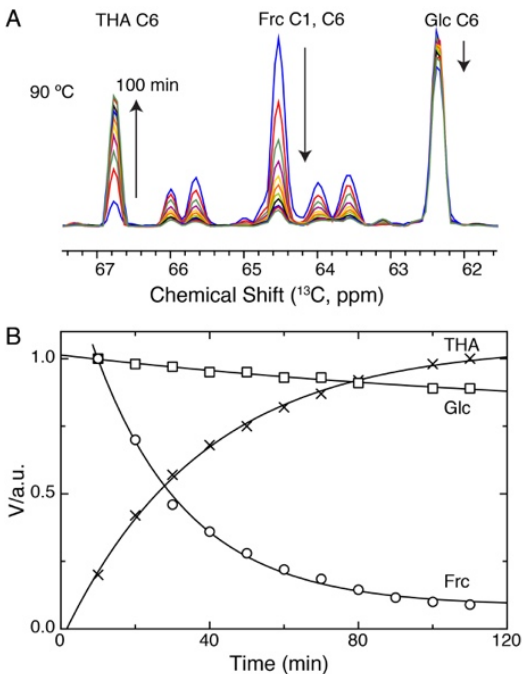

Figure 3. $(A, B)$ Projections of the $2 \mathrm{D}{ }^{1} \mathrm{H}-{ }^{13} \mathrm{C}$ HSQC spectra onto the ${ }^{13} \mathrm{C}$ dimension for a reaction comparing fructose and glucose conversion under identical reaction conditions. ${ }^{1} \mathrm{H}-{ }^{13} \mathrm{C}$ HSQC was used to to obtain ${ }^{13} \mathrm{C}$ spectra with increased sensitivity while tracking the reaction in situ $(0.5 \mathrm{M}$ glucose, 0.5 $\mathrm{M}$ fructose, $0.1 \mathrm{M} \mathrm{SnCl}_{4}, 90^{\circ} \mathrm{C}$ ). Spectra of 10 minutes duration were recorded and the first ten spectra are shown. (B) Reaction progress showing higher reactivity of fructose as compared to glucose.

Higher reactivity of fructose than of glucose is inherent to both open-chain and cyclic reaction pathways, as the open and the furanose form are higher populated in fructose than in glucose. In situ ${ }^{1} \mathrm{H}-{ }^{13} \mathrm{C}$ HSQC NMR spectroscopy at optimized reaction conditions was thus employed for a competitive in situ assay between isomeric species to probe the conversion of all linear aldohexoses in a reaction mixture (Figure S7). Figure 4 shows the resultant reaction profiles with a significantly different kinetics of cyclic hexose conversion, where glucose reacted slowest and idose fastest. This trend parallels the highest expected stability of pyranose forms for glucose and lowest stability of pyranose forms for idose as a consequence of the spatial distribution of nonhydrogen substituents at the 6-membered ring (all-equatorial for glucose and all-axial for idose). ${ }^{[14]}$

A comparison of the initial rate of carbohydrate conversion and of open chain populations previously determined in water indicated a correlation between open chain population and reaction rate (Figure 4B). Metal chlorides have previously been suggested to catalyze the anomerization of glucose and fructose in acyclic form. ${ }^{[3 b]}$ The observed correlation between the rate of conversion and fraction of acyclic aldohexose is consistent with a rapid pre-equilibrium between cyclic and open aldohexose forms, prior to a rate-limiting conversion of the open substrate to the reactive complex between acyclic form and metal. If the ratelimiting formation of reactive complex from open substrate is designated with rate constant $k_{\text {complex }}$, then the rate of complex formation $d[$ complex $] / d t=k_{\text {complex }} \cdot$ [open $]$ depends on the equilibrium constant $K$ between open and dominant cyclic species as $d[$ complex $] / d t=k_{\text {complex }} \cdot K \cdot[$ cyclic $]$. Faster conversion of substrates with higher acyclic population (higher $K$ ) and possible structural details in hydroxyl group orientation

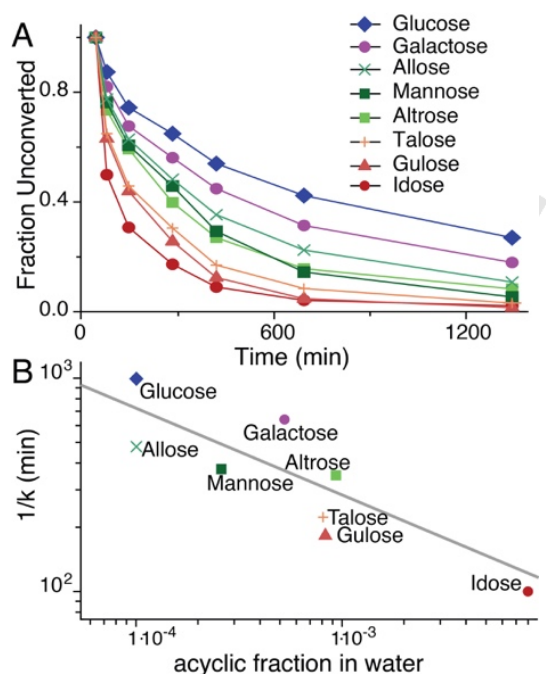

Figure 4. Kinetic profile for the conversion of all aldohexoses at $100{ }^{\circ} \mathrm{C}(\mathrm{A})$ and correlation of reaction rates to previously determined acyclic fractions (drawn on a double logarithmic scale in B). Conversion was tracked in situ by ${ }^{1} \mathrm{H}^{-13} \mathrm{C}$ HSQC NMR spectroscopy on a reaction mixture of all aldohexoses (10 mg each, $0.1 \mathrm{M} \mathrm{SnCl}_{4}$ in $600 \mu \mathrm{ld} 6-\mathrm{DMSO}$ ) to warrant identical reaction conditions for all substrates.

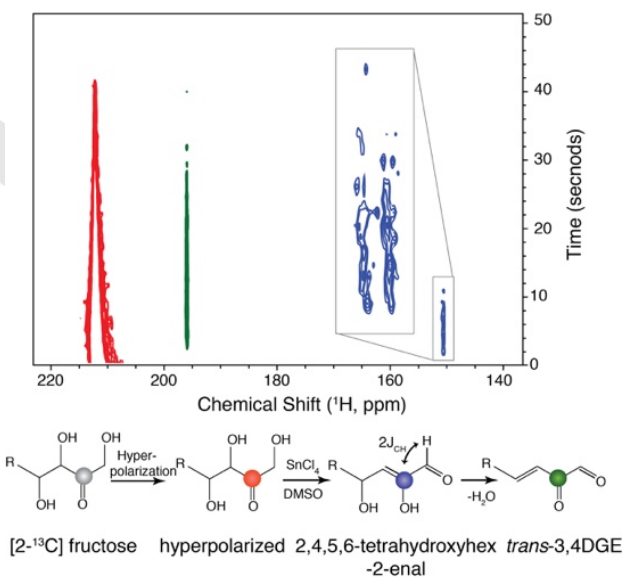

Figure 5. Hyperpolarized ${ }^{13} \mathrm{C}$ NMR experiment of initial steps of $\left[2-{ }^{13} \mathrm{C}\right]$ fructose conversion at $70{ }^{\circ} \mathrm{C}$ in DMSO by $\mathrm{SnCl}_{4}\left(0.1 \mathrm{M}\right.$; top). A time series of $1 \mathrm{D}^{13} \mathrm{C}$ spectra is displayed, where the overall signal fades due to the loss of transient nuclear spin hyperpolarization. Time resolved ${ }^{13} \mathrm{C}$ spectra show the formation of an enol species as the initial detectable intermediate.

influencing the rate of conversion (here through $\left.k_{\text {complex }}\right)^{[15]}$ may thus account for kinetic differences displayed in Figure 4. Combined, these studies indicate the value of employing competitive in situ experiments for determining plausible routes of hexose conversion.

In order to obtain further mechanistic insight into the routes of hexose conversion, in situ NMR was conducted to track reactions and address the following: (1) what are the earliest intermediates detectable upon carbohydrate-catalyst interaction, (2) is it possible to rationalize different selectivity to cis and trans olefinic bonds upon dehydration and (3) is HMF formed through the linear pathway? The detection of early intermediates requires 


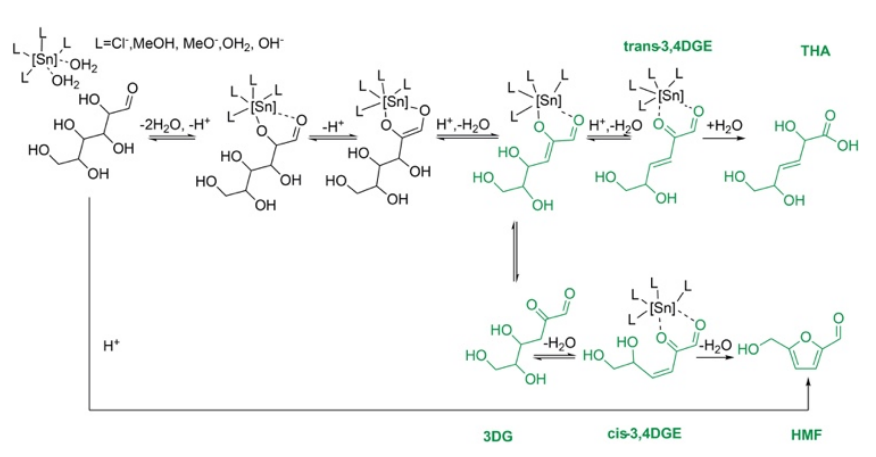

Scheme 2. Plausible reaction scheme consistent with in situ kinetic data described herein for the conversion of glucose to THA (trans-2,5,6-trihydroxy3-hexenoic acid) and HMF (5-hydroxymethylfurfural) in $\mathrm{DMSO} / \mathrm{SnCl}_{4}$. Directly observed intermediates and products are highlighted in green. Partial hydrolysis of $\mathrm{SnCl}_{4}$ to active species has previously been reported ${ }^{[16]}$ and catalytic [Sn] Lewis acid sites are shown in a generalized manner.

a short experimental dead time and sufficiently rapid, sensitive and information-rich experiments. Hyperpolarized NMR is a means to temporarily creating non-equilibrium nuclear spin magnetization that provides $\sim 10,000$-fold enhanced signal on the sub-minute timescale. Hyperpolarized ${ }^{13} \mathrm{C}$ NMR was employed due to the rich structural information of the ${ }^{13} \mathrm{C}$ NMR signal, due to the high reactivity of fructose and due to its commercial availability as $\left[2-{ }^{13} \mathrm{C}\right]$-fructose. The experiment shows the initial formation of an enol at C2 in 2,4,5,6-tetrahydroxyhex-2-enal (Figure 5), with the ${ }^{13} \mathrm{C} 2$ signal split in a characteristic manner by the adjacent aldehyde proton at $\mathrm{C} 1$. This species is converted to trans-3,4 DGE (Scheme 2, Figure 6), which accumulates to levels that make it conveniently detectable in conventional NMR reaction progress kinetic analysis. Assignment spectra of the intermediates identified by conventional NMR are shown in Figures S2 and S7.

Spectroscopic observation of the acyclic pathway makes it evident that the formations of trans-3,4 DGE is largely favoured over the formation of cis-3,4 DGE (Figure 6). Due to the high reactivity of the fructose in $\mathrm{SnCl}_{4} / \mathrm{DMSO} /$ water, kinetic experiments were conducted in the range between $40^{\circ} \mathrm{C}$ and 100 ${ }^{\circ} \mathrm{C}$ to establish the activation energy for trans-3,4 DGE and cis3,4 DGE formation from fructose (Figure S8). Trans-3,4 DGE forms approximately threefold faster than cis-3,4 DGE (Figure 6), with the activation energy of trans-3,4 DGE formation being $\sim 3$ $\mathrm{kJ} / \mathrm{mol}$ lower than that of cis-3,4 DGE formation $(107.5 \mathrm{~kJ} / \mathrm{mol}$ as

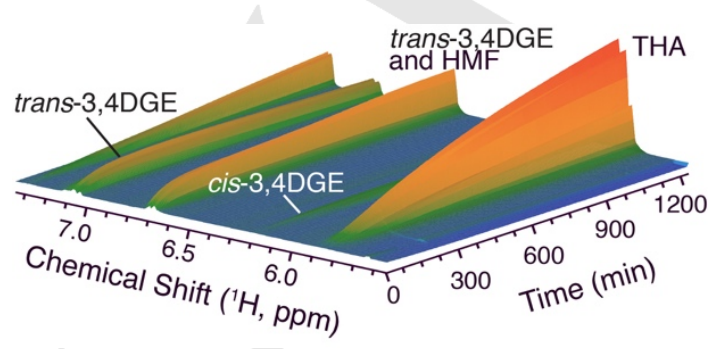

Figure 6. Fructose conversion at $40^{\circ} \mathrm{C}$ as monitored by in situ ${ }^{1} \mathrm{H}$ NMR (fructose (1 M), $\left.\mathrm{SnCl}_{4}(0.1 \mathrm{M}), \mathrm{DMSO} / \mathrm{H}_{2} \mathrm{O}(9: 1(\mathrm{v} / \mathrm{v}))\right)$. compared to $110.5 \mathrm{~kJ} / \mathrm{mol}$, Figure S9), predicting rates of formation that differ by $\mathrm{e}^{\Delta \mathrm{Ea} / \mathrm{RT}} \approx 3$ as observed.

Kinetic data for the conversion of fructose to trans-3,4 DGE and THA fitted well with a mechanism of sequential irreversible elementary reactions on one pathway (Figure S10). In contrast, reaction profiles did not fit well with a sole conversion of cis-3,4 DGE to HMF, indicating that HMF in part forms through a cyclic mechanism from fructose, not unexpected in the presence of accumulating Brønsted acidic THA (Figure S10). A kinetic model describing the formation of THA via trans-3,4 DGE and of HMF from cis-3,4 DGE or from a cyclic pathway is shown in Figure 7. In situ experiments were conducted in the presence and in the absence of added water (Figure S11) to probe the effect of water on pathway steps. Resultant fits of the model to kinetic data in the presence and in the absence of added water are shown in Figure 7. The apparent rate constant $k_{l}$ of the kinetic model integrates contributions from open chain substrate concentration, catalyst complexation and dehydration, while rate the apparent rate constant $k_{2}$ includes a contribution from water concentrations. As expected, $k_{2}$ is thus increased in the presence of water. In contrast, cyclic, Brønsted acid catalyzed dehydrations to HMF are strongest reduced in rate $\left(k_{4}\right.$ and $\left.k_{5}\right)$ in the presence of water. This finding is consistent with the increased selectivity for THA and with the hypothesized stabilization of acidic protons and indirect deceleration of possible Brønsted acid catalyzed pathways to HMF in the presence of water. ${ }^{[11]}$
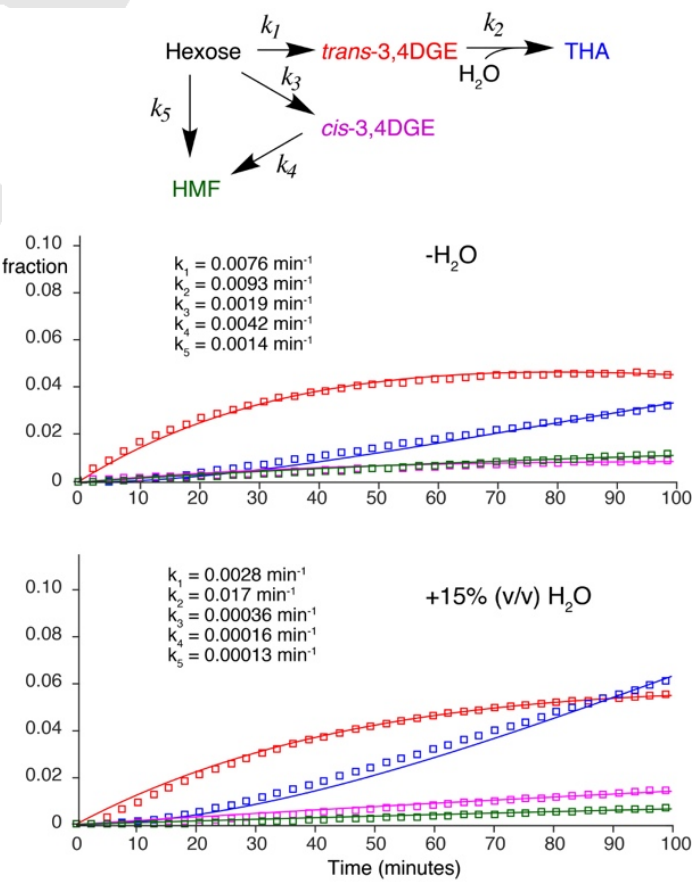

Figure 7. Kinetic analysis (model displayed on top) of in situ NMR spectra for the conversion of $1 \mathrm{M}$ fructose $\left(0.1 \mathrm{M} \mathrm{SnCl}_{4}, 323 \mathrm{~K}\right)$ in $600 \mu \mathrm{ld} 6-\mathrm{DMSO}$ (middle) and in $600 \mu \mathrm{ld} 6-\mathrm{DMSO} / \mathrm{D}_{2} \mathrm{O}(85 / 15 \mathrm{v} / \mathrm{v}$, bottom).

In conclusion, we find that an approach combining serendipitous screening by quantitative NMR and systematic improvement by modulation of solvent properties affords high 
selectivities for the non-commercial C6-compound THA and sheds light on pathways that compete with HMF production. Mechanistic studies are consistent with a chelation of acyclic species by the Sn(IV) catalyst, followed by dehydration at $\mathrm{C} 3$ to form a 2-enol-1-aldehyde species as the first intermediate. Kinetic data were consistent with a sequential reaction of trans-3,4 DGE to THA and of cis-3,4 DGE to HMF, with another (presumably cyclic) pathway contributing to HMF formation from fructose. Acyclic pathways to HMF through 3-deoxyglucosone and cis-3,4 DGE have previously been suggested based on computational studies $^{[3 e, 6 b, 17]}$ and on the experimental observation of cis-3,4 DGE in carbohydrate- and HMF-containing solutions. ${ }^{[18]}$ DMSO is an attractive solvent for the reaction due to its ability to solubilize carbohydrates and to reduce humin formation compared to aqueous solvents. Further improvements using biphasic systems $^{[3 a]}$ in order to minimize humin formation and to facilitate purification, or use of buffer in order to avoid mechanistic changes due to the formation of free Brønsted acid could be envisioned. The suitability of heterogeneous Sn(IV) catalysts in aprotic solvents for the catalysis of acyclic carbohydrate conversion pathways is under investigation. We finally note that the pathways described herein have biochemical counterparts in the formation of highly reactive glucose degradation products linked to cytotoxicity and diabetic complications ${ }^{[18 b, 19]}$ Mechanistic studies of these biochemical processes in water may be facilitated by the current pathway study.

\section{Experimental Section}

Reaction mixtures containing carbohydrate in $d_{6}$-DMSO with catalyst (10$\mathrm{mol} \%$ ) and defined water fraction were incubated under shaking (600 rpm at $100{ }^{\circ} \mathrm{C}$ for 20 hours in an Eppendorf Thermomixer). Samples were transferred to $5 \mathrm{~mm}$ NMR sample tubes after the reaction and immediately analysed at $30{ }^{\circ} \mathrm{C}$ by ${ }^{1} \mathrm{H}$ and ${ }^{13} \mathrm{C}$ NMR spectroscopy. Samples yielded some discolouring due to humin formation, but remained transparent (albeit slightly coloured) for the experiments with best THA selectvities. Selectivities were estimated by comparing ${ }^{13} \mathrm{C}$ NMR signal (inverse gated ${ }^{13} \mathrm{C} 1 \mathrm{D}$ experiment using a recycling delay of 10 seconds, comparing primary alcohol signals of glucose, fructose and THM C6) integrals of a substrate solution with the product mixture (both normalized to the $d_{6-}$ DMSO signal).

In situ experiments were performed by transferring reaction mixtures from $1.5 \mathrm{ml}$ Eppendorf safelock tubes directly to NMR tubes and heating samples to the desired temperature in the spectrometer. Reaction progress was then followed by pseudo-2D spectra recording a series of ${ }^{1} \mathrm{H}$ or ${ }^{13} \mathrm{C}$ NMR spectra in real time. Comparison of glucose and fructose and comparison of reactivity of the linear aldohexoses was conducted using ${ }^{1} \mathrm{H}-{ }^{13} \mathrm{C}$ HSQC spectra and initial rates were approximated by an exponential fit. NMR spectra were recorded, processed and analysed with Bruker Topspin software. Kinetic data of reaction progress of fructose conversion at 40,70 or $100{ }^{\circ} \mathrm{C}$ were integrated in Bruker Topspin 3.0 and fitted to a model of sequential elementary reactions in proFit 7 (Quantum Soft, Switzerland).

Isotope-enriched $\left[2-{ }^{13} \mathrm{C}\right]$-fructose (Cambridge Isotope Laboratories, Tewksbury, MA) was hyperpolarized using a HyperSense (Oxford Instruments, England) polarizer with a magnetic field of $3.35 \mathrm{~T}$. Solid-state polarizations of $\sim 30 \%$ were obtained in the self-glassing carbohydrate syrup. After 1 hour of polarization, the samples were dissolved with heated Milli-Q water to yield liquid hyperpolarized $\left[2-{ }^{13} \mathrm{C}\right]-$ fructose samples.
Hyperpolarized ${ }^{13} \mathrm{C}$ NMR experiments were conducted by forcefully injecting $600 \mu \mathrm{l}$ of the aqueous fructose solution into a solution of $\mathrm{SnCl} 4$ in DMSO (100 mg in $4 \mathrm{ml}$ ) equilibrated to $70^{\circ} \mathrm{C}$ in an Oxford $400 \mathrm{MHz}$ magnet. Acquisition of ${ }^{13} \mathrm{C}$ spectra was started prior to the injection. Detailed experimental procedures are described in the Supporting Information.

\section{Acknowledgements}

This work was supported by Innovation Fund Denmark (case number 5150-00023B). All $800 \mathrm{MHz}$ NMR spectra were recorded on the spectrometer of the NMR center DTU supported by the Villum Foundation.

Keywords: carbohydrate $\cdot$ Lewis acid $\bullet$ qNMR reaction kinetics - reaction mechanism

[1] a) C. B. Field, M. J. Behrenfeld, J. T. Randerson, P. Falkowski, Science 1998, 281, 237-240; b) R.-J. van Putten, J. C. van der Waal, E. de Jong, C. B. Rasrendra, H. J. Heeres, J. G. de Vries, Chemical Reviews 2013, 113, 1499-1597.

[2] a) B. Kamm, M. Kamm, CABEQ 2004, 18, 1-6; b) K. J. Ptasinski, in Efficiency of Biomass Energy, John Wiley \& Sons, Inc., 2015, pp. 673706.

[3] a) Y. Roman-Leshkov, J. N. Chheda, J. A. Dumesic, Science 2006, 312, 1933-1937; b) H. Zhao, J. E. Holladay, H. Brown, Z. C. Zhang, Science 2007, 316, 1597-1600; c) A. S. Amarasekara, L. D. Williams, C. C. Ebede, Carbohydr. Res. 2008, 343, 3021-3024; d) S. Hu, Z. Zhang, J. Song, Y. Zhou, B. Han, Green Chem. 2009, 11, 1746-1749; e) H. Jadhav, C. M. Pedersen, T. Solling, M. Bols, ChemSusChem 2011, 4, 1049-1051; f) C. B. Rasrendra, B. A. Fachri, I. G. Makertihartha, S. Adisasmito, H. J. Heeres, ChemSusChem 2011, 4, 768-777; g) G. R. Akien, L. Qi, I. T. Horvath, Chem. Comm. 2012, 48, 5850-5852; h) G. Tsilomelekis, T. R. Josephson, V. Nikolakis, S. Caratzoulas, ChemSusChem 2014, 7, 117126.

[4] a) H.-S. Chen, A. Wang, H. Sorek, J. D. Lewis, Y. Román-Leshkov, A. T. Bell, ChemistrySelect 2016, 1, 4167-4172; b) S. Tolborg, S. Meier, I. Sádaba, S. G. Elliot, S. K. Kristensen, S. Saravanamurugan, A. Riisager, P. Fristrup, T. Skrydstrup, E. Taarning, Green Chem. 2016, 18, 33603369; c) S. G. Elliot, C. Andersen, S. Tolborg, S. Meier, I. Sádaba, A. E. Daugaard, E. Taarning, RSC Adv. 2017, 7, 985-996.

[5] a) M. J. Antal Jr, T. Leesomboon, W. S. Mok, G. N. Richards, Carbohydr. Res. 1991, 217, 71-85. b) X. Qian, M. R. Nimlos, M. Davis, D. K. Johnson and M. E. Himmel, Carbohydr. Res., 2005, 340, 2319-2327.

[6] a) S. H. Mushrif, S. Caratzoulas, D. G. Vlachos, Phys. Chem. Chem. Phys. 2012, 14, 2637-2644; b) S. Kunnikuruvan, N. N. Nair, ACS Catal. 2019, 9, 7250-7263.

[7] T. Wang, M. W. Nolte, B. H. Shanks, Green Chem. 2014, 16, 548-572.

[8] a) S. Meier, M. Karlsson, P. R. Jensen, ACS Sustainable Chem. Eng. 2017, 5, 5571-5577; b) W. Plazinski, A. Plazinska, M. Drach, Phys. Chem. Chem. Phys. 2016, 18, 9626-9635.

[9] a) M. Bojstrup, B. O. Petersen, S. R. Beeren, O. Hindsgaul, S. Meier, Anal. Chem. 2013, 85, 8802-8808; b) S. Meier, Anal. Bioanal. Chem. 2014, 406, 7763-7772; c) B. O. Petersen, O. Hindsgaul, S. Meier, Analyst 2014, 139, 401-406.

[10] R. R. Forseth, F. C. Schroeder, Curr. Opin. Chem. Biol. 2011, 15, 38-47.

[11] M. A. Mellmer, C. Sener, J. M. R. Gallo, J. S. Luterbacher, D. M. Alonso, J. A. Dumesic, Angew. Chem. Int. Ed. 2014, 53, 11872-11875.

[12] a) D. Padovan, L. Botti, C. Hammond, ACS Catalysis 2018, 8, 71317140; b) D. Padovan, S. Tolborg, L. Botti, E. Taarning, I. Sádaba, C. Hammond, React. Chem. Eng. 2018, 3, 155-163; c) I. Tosi, A. Riisager, E. Taarning, P. R. Jensen, S. Meier, Catal. Sci. Technol. 2018, 8, 21372145 . 
[13] S. Tolborg, I. Sádaba, C. M. Osmundsen, P. Fristrup, M. S. Holm, E. Taarning, ChemSusChem 2015, 8, 613-617.

[14] Y. Zhu, J. Zajicek, A. S. Serianni, J. Org. Chem. 2001, 66, 6244-6251.

[15] R.-J. van Putten, J. C. van der Waal, M. Harmse, H. H. van de Bovenkamp, E. de Jong, H. J. Heeres, ChemSusChem 2016, 9, 18271834

[16] K. R. Enslow, A. T. Bell, Catalysis Science \& Technology 2015, 5, 28392847.

[17] H. Rasmussen, H. R. Sørensen, A. S. Meyer, Carbohydrate Research 2014, 385, 45-57.
[18] a) M. Hellwig, A. Nobis, S. Witte, T. Henle, J. Agric. Food Chem. 2016, 64, 2746-2753; b) T. Linden, A. Cohen, R. Deppisch, P. Kjellstrand, A. Wieslander, Kidney Int. 2002, 62, 697-703.

[19] P. J. Thornalley, A. Langborg, H. S. Minhas, Biochemical J. 1999, 344, 109-116. 
Entry for the Table of Contents (Please choose one layout)

Layout 1:

\section{COMMUNICATION}

Serendipitous and systematic

approaches are combined to

triple the yield of a non-

commercial compound directly

from glucose and to make the

acyclic pathway of carbohydrate

conversion accessible to

observation.

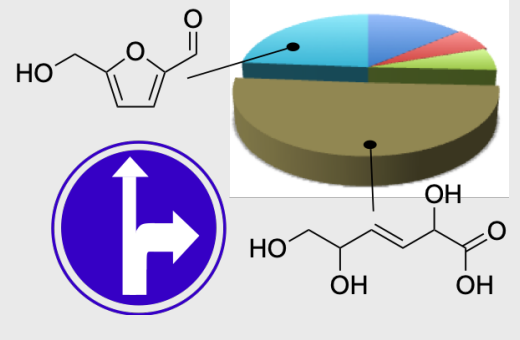

Esben Taarning, Irantzu Sádaba,

Pernille Rose Jensen, and Sebastian Meier*

Page No. - Page No.

Discovery and Exploration of the Efficient Acyclic Dehydration of Hexoses in DMSO/Water

Layout 2:

\section{COMMUNICATION}

((Insert TOC Graphic here))
Author(s), Corresponding Author(s)*

Page No. - Page No.

Title 